\title{
GROWTH IN CHILDREN WITH CONGENITAL HEART DISEASES.
}

\section{Eman Mahmoud elmoghazy, Alshayma Ahmed Ali , Naglaa Ali khalifa * pediatrics and clinical pathology *departments, faculty of medicine ,Zagazig university.}

Ahmed Mohamed Salah M. B. B. Ch, zagazig university.

\section{ABSTRACT}

Background:Children with congenital heart disease (CHD) commonly experience delayed growth. Because growth and development are closely related, both should be considered when a child's progress is examined.A longitudinal study was made of height and weight growth in children with cyanotic and acyanotic congenital heart disease. Values were compared to agroup of children without heart disease. Retardation in height and weight was noted in all children with cardiac disease but was more pronounced in those with cyanosis.

Aim: To compare growth in children with congenital heart disease and normal children. Materials and Method :casecontrol study, the study took place in out_patient clinic and cardiology unit of pediatric department of faculty of medicine in Zagazig Univesity of Zagazig University Hospitals This study was conducted on 30 infants \& children ( 16 males \& 14 females )with congenital heart diseases attending the pediatric cardiology unit in zagazig University hospital, over a period of 6 months from february 2017 till July 2017, their age ranged from 2 months to 2 years old. Thirty healthy children of sex \& age matched to patients were taken as control group. Results :Asignificant difference was found in both body height $(\mathrm{P}<0.05)$ and weight $(\mathrm{P}<0.05)$ between the two groups. More children with congenital heart disease were below the 50th percentile in height $(\mathrm{P}<0.05)$ and weight $(\mathrm{P}<0.001)$. Conclusion:Children with CHD were retarded in growth than normal children. Learning about the growth and developmental differences between children with CHD and normal children may help parents of the former to detect problems associated with delayed growth and development earlier. Keywords: growth, development, nursing, congenital heart disease, children.

Corresponding author: Ahmed Mohamed Salah Salem.

E mail: doc.ped2020@gmail.com

Tel : 01064144135

\section{INTRODUCTION}

$\mathbf{T}$ o evaluate the growth and development in young children, especially those with congenital diseases, it is necessary to identify developmental delays and provide access to early intervention ${ }^{[6]}$ Children with congenital heart disease (CHD) have been reported to show significant growth retardation both prenatally and postnatally. Retardation in height as well as weight seems most pronounced in children with cyanotic heart disease $^{[1]}$. Inadequate caloric intake has been shown to be the most important cause of growth disturbances in children with CHD , Several possibilities have been proposed to explain the decreased intake in these patients including fatigue upon feeding and malabsorption $^{[2]}$ Hypoxia results from imbalances between oxygen demand and supply. It has been shown that chronic hypoxia has many effects on the endocrine system, mainly on growth ${ }^{[3]}$.Decreased energy intake, increased energy requirements, or malabsorption would be related to malnutrition and GR in children with cyanotic $\mathrm{CHD}^{[4]}$. From infancy, children with $\mathrm{CHD}$ endure more sicknesses, physical examinations, surgical procedures and hospitalizations than normal children. In addition, they are often overprotected and spoiled by their parents; such actions have profound effects on their mood and psychosocial and physical development ${ }^{[5]}$. We aim in this study to compare growth in children with congenital heart disease and normal children.

\section{PATIENTS AND METHODS}

This study was conducted on 30 infants \& children ( 16 males \& 14 females )with congenital heart diseases attending the pediatric cardiology unit in zagazig University hospital, over a period of 6 months from february 2017 till July 2017, their age ranged from 2 months to 2years old. Thirty healthy children of sex \& age matched to patients were taken as control group. Comparison between both groups was done in weight, Height, Body mass index(BMI), head circumference $(\mathrm{HC})$ and $\mathrm{O}_{2}$ level by pulse oximetry as well.

Ethical considerations: Ethical approval was obtained from both the hospitals and preschools selected for this study. The purpose and method of this research was explained to the primary caregiver of each child with heart disease; after giving consent, 
the caregiver signed a research agreement and The children were divided into 3 groups: Group (I) : control group : 30 children (14 males and 16 Females ) their mean age was $(16.3 \pm 4.95)$ months . Healthy children were randomly chosen among patients with no heart disease visiting children general clinic of zagazig university hospital.

Group (II) : Acyanotic group : 15 patients (8 males and 7 Females ) their mean age was

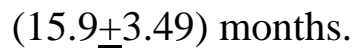

Group (III) : Cyanotic group : 15 patients (7 males and 8 Females ) their mean age was (15.9+3.49) months.

Inclusion criteria:

* Age group ranged from 2 months to 2 years

*Patients were with CHD as diagnosed by echocardiography.

* Control children were free from other malformations or signs of other disease

\section{Exclusion criteria:}

* Patients with a history of prematurity, intrauterine growth retardation, known genetic malformations, dysmorphic features, and neurologic disability were excluded.

* patients with other cardiac lesions as rheumatic heart disease and cardiomyopathy .

DATA ANALYSIS completed a basic information form.

Data were statistically described in terms of range, mean \pm standard deviation ( \pm SD), median, frequencies (number of cases) and percentages when appropriate. Comparison of quantitative variables between the study groups was done using analysis of variance (ANOVA) test with Mann Whitney $U$ test for independent samples as posthoc multiple 2group comparisons. For comparing categorical data, Chi square $\left(\chi^{2}\right)$ test was performed. Exact test was used instead when the expected frequency is less than 5 . Correlation between various variables was done using Pearson moment correlation equation for linear relation. A probability value ( $p$ value) more than 0.05 was considered statistically insignificant, when it was less than 0.05 was considered statistically significant and when $<0.01$ it was considered statistically highly significant . All statistical calculations were done using computer programs Microsoft Excel 2007 (Microsoft Corporation, NY, USA) and SPSS (Statistical Package for the Social Science; SPSS Inc., Chicago, IL, USA) version 15 for Microsoft Windows.

\section{RESULTS}

Table (1): Studying of demographic data in between the studied groups:

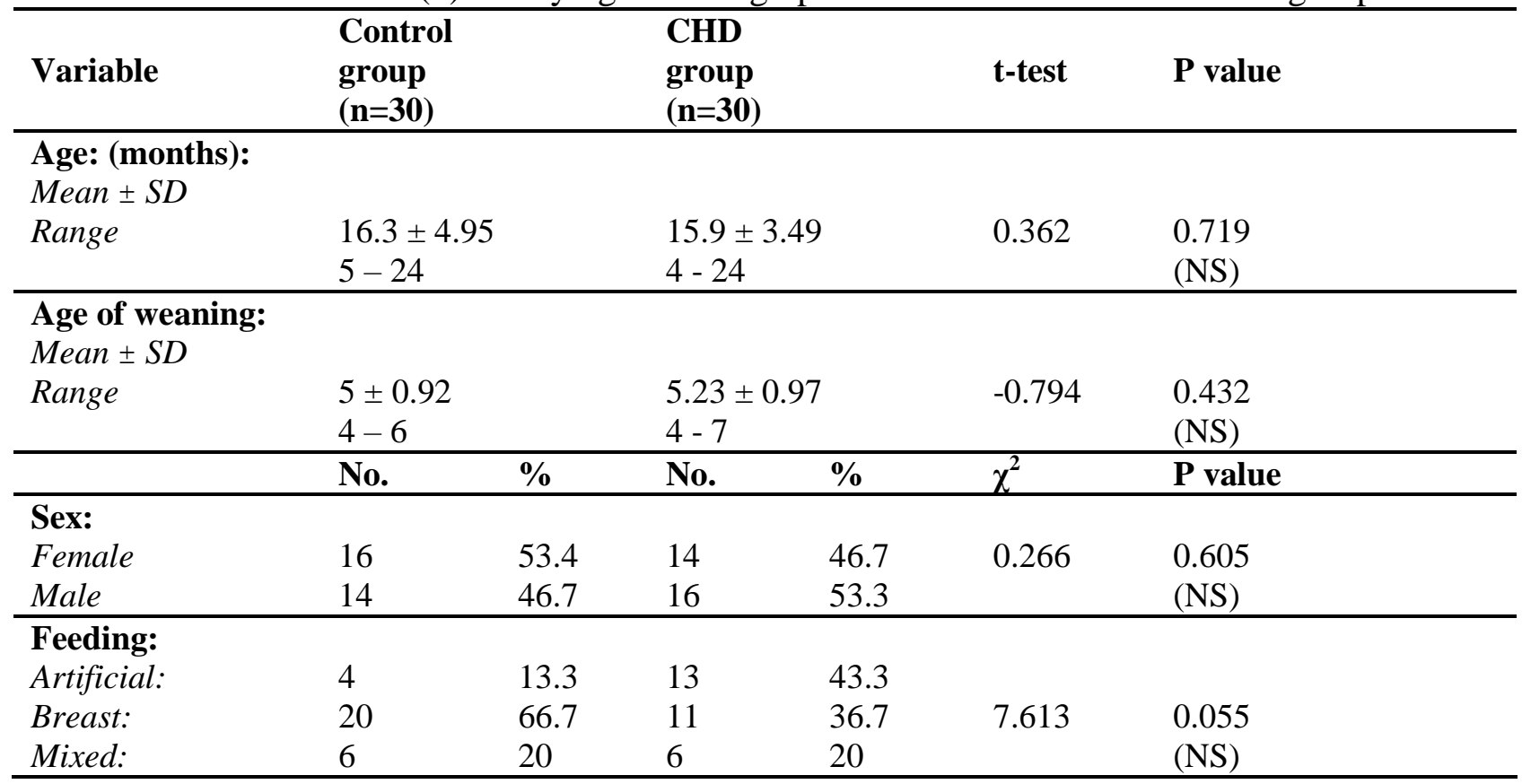


This table shows that there was non-significant difference between the studied groups as regarding age of babies, age of weaning, sex and feeding pattern.

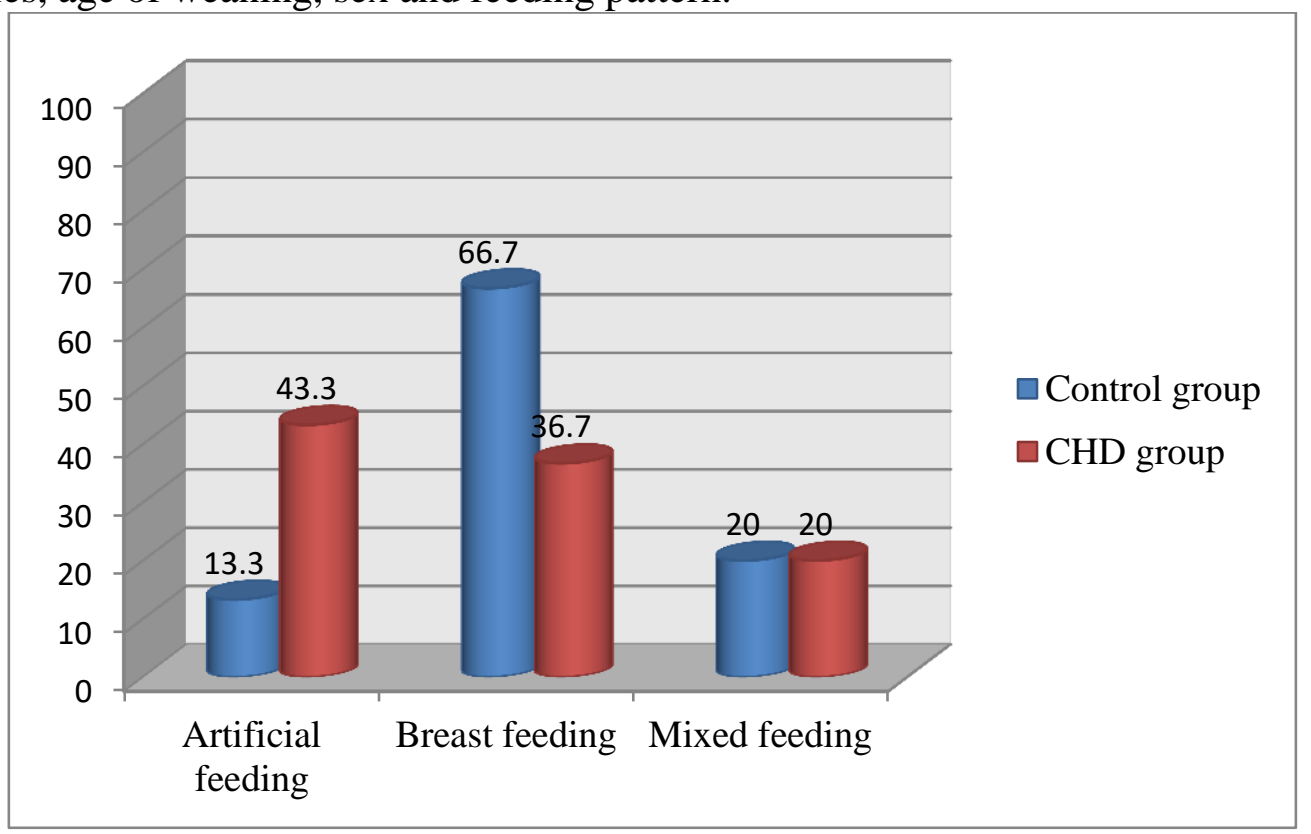

Figure (1): Bar chart showing feeding modalities among the studied groups.

Table (2): Studying of anthropometric measurements of the studied groups:

\begin{tabular}{|l|l|l|l|l|}
\hline Variable & $\begin{array}{l}\text { Control } \\
\text { group } \\
(\mathbf{n = 3 0})\end{array}$ & $\begin{array}{l}\text { CHD } \\
\text { group } \\
(\mathbf{n = 3 0})\end{array}$ & t-test & P value \\
\hline $\begin{array}{l}\text { Weight:(kg) } \\
\begin{array}{l}\text { Rean } \pm S D \\
\text { Range }\end{array}\end{array}$ & $\begin{array}{l}12.04 \pm 1.72 \\
8-16\end{array}$ & $\begin{array}{l}7.01 \pm 2.51 \\
4-12\end{array}$ & $\mathbf{9 . 0 4 5}$ & $\begin{array}{l}<\mathbf{0 . 0 0 1} \\
(\mathbf{H S})\end{array}$ \\
\hline $\begin{array}{l}\text { Height: }(\mathbf{c m}) \\
\text { Mean } \pm S D\end{array}$ & $\begin{array}{l}83.8 \pm 6.23 \\
\text { Range }\end{array}$ & $\begin{array}{l}67.8 \pm 12.3 \\
55-97\end{array}$ & $\mathbf{6 . 3 4 0}$ & $\begin{array}{l}<\mathbf{0 . 0 0 1} \\
(\mathbf{H S})\end{array}$ \\
\hline $\begin{array}{l}\text { BMI: } \\
\text { Mean } \pm S D\end{array}$ & $\begin{array}{l}17.2 \pm 1.32 \\
\text { Range }\end{array}$ & $\begin{array}{l}14.8 \pm 1.93 \\
12.7-18.9\end{array}$ & $\mathbf{5 . 4 4 1}$ & $\begin{array}{l}<\mathbf{0 . 0 0 1} \\
(\mathbf{H S})\end{array}$ \\
\hline $\begin{array}{l}\text { HC: }(\mathbf{c m}) \\
\text { Mean } \pm S D \\
\text { Range }\end{array}$ & $\begin{array}{l}46.4 \pm 1.71 \\
44-51\end{array}$ & $\begin{array}{l}43.5 \pm 4.85 \\
38-48\end{array}$ & $\mathbf{3 . 0 8 5}$ & $\begin{array}{l}\mathbf{0 . 0 0 3} \\
(\mathbf{S})\end{array}$ \\
\hline $\begin{array}{l}\text { MAC: }(\mathbf{c m}) \\
\begin{array}{l}\text { Mean } \pm S D \\
\text { Range }\end{array}\end{array}$ & $12.2 \pm 0.76$ & $11.3 \pm 1.26$ & $\mathbf{3 . 2 9 1}$ & $\begin{array}{l}\mathbf{0 . 0 0 2} \\
(\mathbf{S})\end{array}$ \\
\hline
\end{tabular}

$\mathrm{HC}=$ head circumference, $\mathrm{BMI}=$ body mass index , MAC=mid arm circumference.

This table shows that there was highly significant difference between the studied groups as regarding weight, height and body mass index with those parameters were significantly higher in control group when compared to CHD group.
As regarding head and mid arm circumference, control group had significantly higher circumferences when compared to CHD group (46.4, 12.2 versus 43.5, 11.3 respectively). 


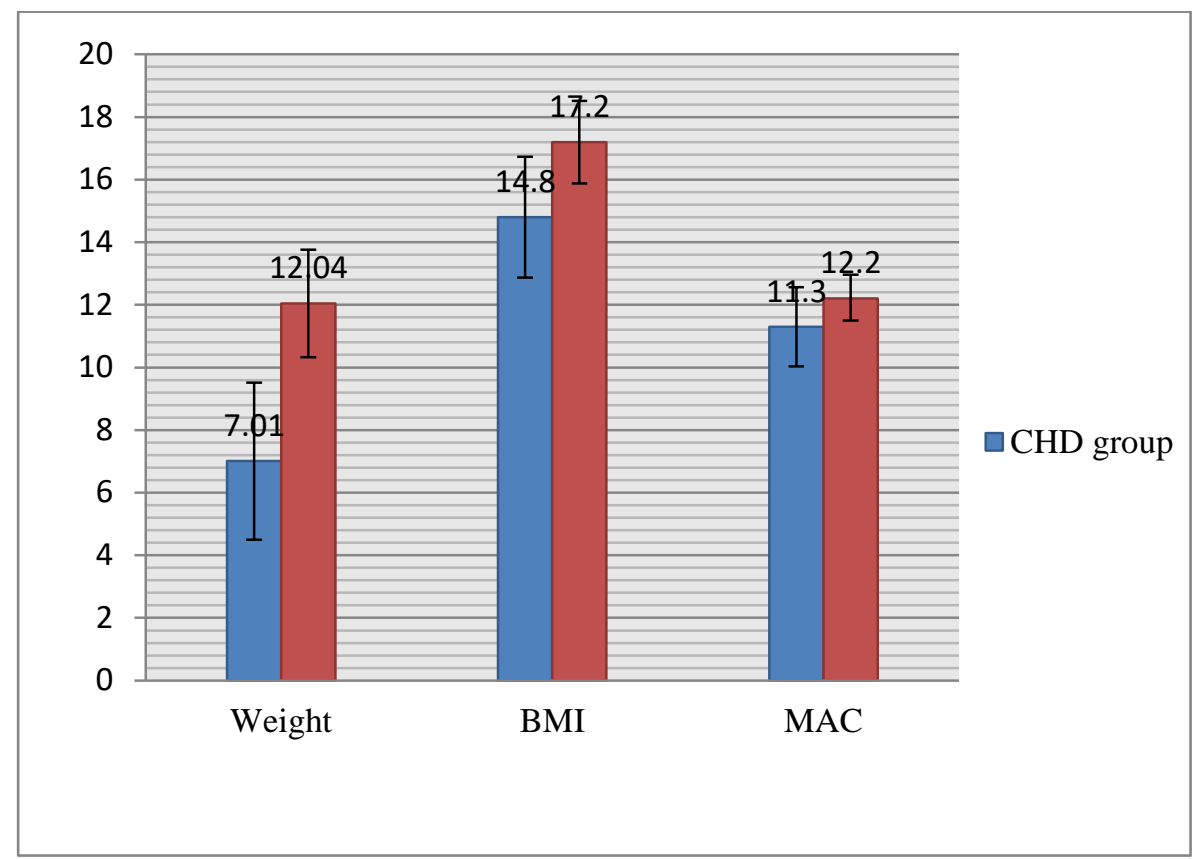

Figure (2): Bar chart showing anthropometric measurements among the studied groups.

Table (3): Oxygen level by pulse oximetry of the studied groups:

\begin{tabular}{|l|l|l|l|l|l|}
\hline Variable & $\begin{array}{l}\text { Control } \\
\text { group } \\
(\mathbf{n = 3 0})\end{array}$ & $\begin{array}{l}\text { Acyanptic } \\
\text { CHD } \\
(\mathbf{n = 1 5})\end{array}$ & $\begin{array}{l}\text { Cyanptic } \\
\text { CHD } \\
(\mathbf{n = 1 5})\end{array}$ & $\mathbf{F}$ & $\mathbf{p}$ \\
\hline $\begin{array}{l}\text { O2 level: } \\
\text { Mean } \pm S D\end{array}$ & $\begin{array}{l}98.1 \pm 0.52 \\
\text { Range }\end{array}$ & $\begin{array}{l}89.4 \pm 1.21 \\
91-99\end{array}$ & $\begin{array}{l}68.4 \pm 3.44 \\
62-76\end{array}$ & $\mathbf{1 3 1 . 5}$ & $\begin{array}{l}<\mathbf{0 . 0 0 1} \\
(\mathbf{H S})\end{array}$ \\
\hline
\end{tabular}

This table shows that there was highly significant difference between the studied groups as regarding oxygen level measured by pulse oximetry.It was noticed that oxygen level was significantly lower in cyanotic group than in control and acyanotic groups (68.4, 98.1 and 89.4 respectively).

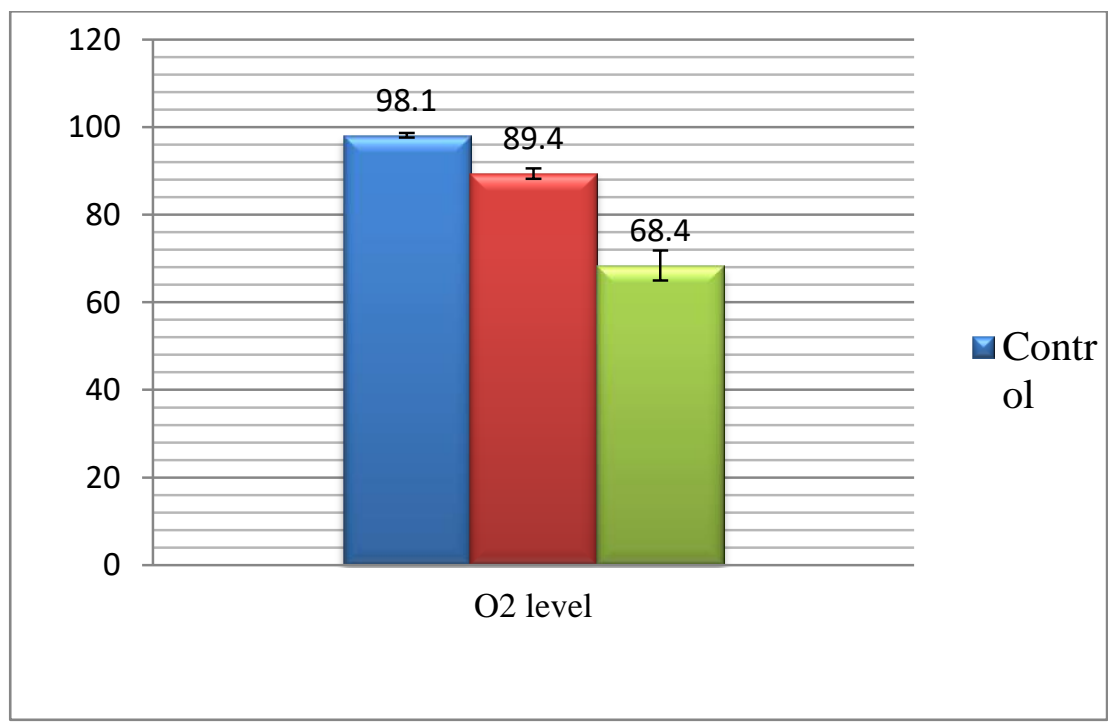

Figure (3): Bar chart showing oxygen levels among the studied groups. 


\section{DISCUSSION}

Children with CHD experience delayed growth because of possible genetic influences, tissue hypoxia, reduced cardiac output, pulmonary hypertension, repeated respiratory tract infections and malnutrition . In some patients with congenital heart disease, growth retardation is marked, but clinical and physiological studies show little deviation from the normal state. In such instances, the growth retardation is thought to be primarily due to genetic or in utero factors, or, if secondary, secondary to something other than the heart lesion itself. Emotional disturbances can be an important secondary cause of poor growth in this regard [9] . Although the children in our study were young when they had surgery, CHD significantly affected their growth. there was highly significant difference between the studied groups as regarding weight, height and body mass index with those parameters were significantly higher in control group when compared to CHD group. As regarding head and mid arm circumference, control group had significantly higher circumferences when compared to CHD group (46.4, 12.2 versus 43.5, 11.3 respectively). Their slower growth is consistent with other studies. Growth height and growth weight were not significantly different between children with CHD and normal children. Although the birth weights of children with CHD were lower, they experienced considerable growth. Severe failure to thrive (height and weight below the third percentile) was observed in $13 \%$ of the children with CHD but in only $1 \%$ of the normal children. Benn (1947) has analysed statisticaly the height and weight of school children with patent ductus arteriosus. He found both boys and girls were under weight, the differences for the boys being probably, and for the girls certainly, of statistical significance $^{[7]}$. Mothers of these children often have more frequent changes of residence, more marital problems, and an increased pressure index. Because of this important relationship, the pediatrist must have intimate knowledge of the phenomenon of growth. It is an accepted practice in pediatrics to obtain height and weight measurements as a part of the routine physical examination $^{[8]}$. Information about paternal influence is lacking. In this study, about $80 \%$ of the children with height and weight below the third percentile had parents with an educational level of high school or less, most of their families were in a low socioeconomic group. Thomlinson (2002) surveyed 12 families with children who failed to thrive. The parents felt guilty because their children did not grow, and experienced feelings of isolation and helplessness. Health care professionals must understand the possible effects of their negative comments and actions onthese families.

\section{CONCLUSION}

Significant differences were observed in the physical growth, language development, and gross motor development of preschool children with CHD and normal children. Prompt diagnosis and surgical treatment are needed to minimize the effects of CHD on physiological functions. Equally important is promoting interaction between these children and others in society. Parents play a key role; they should understand the disease and use appropriate childrearing methods. Parents of children with CHD often worry about their children's health and may limit their opportunities for participating in activities or interacting with peers.

\section{REFERENCES}

1- Siliman AT, Elawwa A, Khella A, Saeed S, Yassia H. linear growth in relation to circulating concentration of insulin-like growth factor-1 in young children acyanotic congenital heart disease with left to right shunts before versus after surgical intervention. Indian Journal of Endocrinology and Metablism 2012; 16(5): 791- 795.

2- Leitch CA. Growth, nutrition and energy expenditure in pediatric heart failure. Prog Pediatr Cardiol.. 2000;11(3):195-202

3- Eren E, Cakir EDP, Bostan O, Saglam H, Tarim O. Evaluation of the endocrine functions in pediatric patients with cyanotic 
congenital heart disease. Biomedical Research 2013; 24(2): 211-215.

4- Venugopalan P, Akinbami FO, Al-Hinai KM, Agarwal AK. Malnutrition in children with congenital heart defects. Saudi Med J 2001;22(11): 964-67.

5- Loeffel M. Developmental considerations of infants and children with congenital heart disease. Heart \& Lung: Journal of Critical Care $141985,214-217$.

6- Chao C.C., Chang J.K., Pan W.C., Wu Y.T., Lue H.C. \& Meng C.C.L. Growth disturbance in Chinese children with congenital heart disease. Acta Paediatrica Sinica 25 1984, 386390.

7 - Campbell, M., Reynolds, G. The physical and mental development of children with congenital heart disease. Arch. Dis. Childhood. 1949;24:294.

8- Jackson, R.L., Kelly, H.G. Growth charts for use in pediatric practice. J. Pediat. 1945;27:215.

9- FH Adams, GW Lund, RB Disenhouse - The Journal of Pediatrics, 1954 - Elsevier 